\title{
Effect Evaluation of Fault Resistance on the Operating Behavior of a Distance Relay
}

\author{
Kim Hung Le \\ University of Science and Technology - The University of \\ Da Nang, Da Nang, Vietnam \\ lekimhung@dut.udn.vn
}

\author{
Phan Huan $\mathrm{Vu}$ \\ Center Electrical Testing Company Limited \\ Da Nang, Vietnam \\ vuphanhuan@gmail.com
}

\begin{abstract}
This paper presents an application of a certain distance protection relay with a quadrilateral characteristic approach for the protection of the $110 \mathrm{kV}$ Duy Xuyen - Thang Binh transmission line in Vietnam using measured data from one terminal line. We propose the building process of a Matlab Simulink model for this relay that combines fault detection and classification block, apparent impedance calculation block for all types of faults and a trip logic block of three zone protection coordination. The proposed relay model is further tested using various fault scenarios on the transmission line. It is important to assess what happened, the actual conditions, the causes of maloperation etc. Detailed explanation and results indicate that the proposed model behavior will help users to perform tests which correctly simulate real-world conditions besides that it properly interprets test results and troubleshoot distance function problems when results are not as expected.
\end{abstract}

Keywords-transmission line; distance protection relay; quadrilateral characteristic; logic trip; Matlab/Simulink

\section{INTRODUCTION}

Transmission lines are one of the main components in high voltage and extra high voltage power system. The main protection used to protect Vietnam's transmission lines is a numerical distance protection relay $(\mathrm{F} 21)$ as shown in Figure 1 because of its suitability, simplicity, economy, and reliability. There are now various distance relays that have been implemented by different vendors. These relays help to protect safeguard transmission line from exposure to any type of faults (internal or external) which could intentionally or inadvertently damage electrical equipment and avoid a great effect on the stability of the entire power system. However, the distance protection also faces a number of factors which influence negatively its operation, and thus affect its accurate determination of the measured impedance. This then results in inaccurate fault location determination [1]. A relay device manufacturer, or a power system operator, needs to conduct a simulated use of all test scenarios due to factors such as human factor, fault resistance and load current, coupling of parallel lines, multiple feeder sections, power swing or multi-end sources testing to evaluate the operating behavior of relay's characteristics. Many operators are uncertain about the advantages and disadvantages of mho or quadrilateral characteristic related to fault type, system conditions, and look up the backgrounds of the mal-operation to remove errors. In practice, the relay provides satisfactory results for the operation condition of low resistance faults. But, in the case of high resistance faults, particularly for single phase to earth faults, it measures an incorrect value of fault impedance. Consequently, the relay may over-reach or under-reach depending upon the forward/backward flow direction and the magnitude of fault resistance [2]. In order to prove this issue, the current paper focuses on the algorithm of Siemens 7SA522 relay that uses a quadrilateral characteristic. Thereafter, the $110 \mathrm{kV}$ Duy Xuyen Thang Binh transmission line model is selected as an example of fault simulation and the algorithm relay is tested in Simulink. The proposed model has been assessed under several scenarios. Conclusions based on the results are discussed along with the resistance fault factor affecting the relay's accuracy.

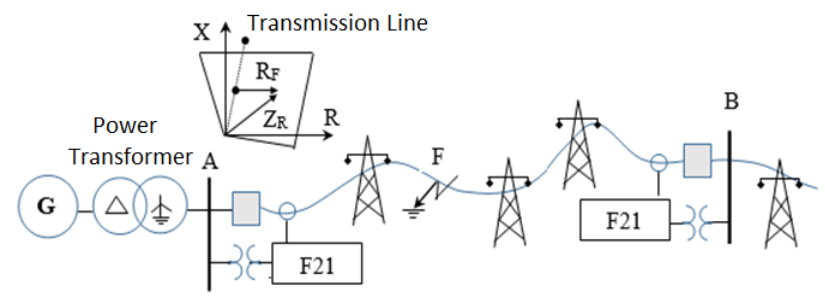

Fig. 1. Distance protection relay on transmission line

\section{RELAY PROTECTION ZONES}

In $[3,4]$, the disadvantage of the Mho relay is that, when it is used on long lines and the reach does not cover the section sufficiently along the resistance axis, it is incapable of detecting faults with high arc or fault resistances. The problem is aggravated in the case of short lines since the setting is low and the amount of the $\mathrm{R}$ axis covered by the mho circle is small in relation to the expected values of arc resistance. So that, the quadrilateral characteristic is a good choice to overcome the disadvantages of mho element when it is properly designed. In the case of medium lines, earth faults can, for instance, be covered with the quadrilateral characteristic and phase faults with the mho characteristic.

In Vietnam, the $110 \mathrm{kV}$ Duy Xuyen-Thang Binh transmission line has length less than $30 \mathrm{~km}$ and, as shown in 
Figure 2, is protected by a Siemens 7SA522 distance protection relay with three forward quadrilateral zones $(Z 1, Z 2, Z 3)$ which provide fault impedance coverage for both phase to phase and phase to earth faults. Setting calculation is important in protection zone setup, so human error can affect the accuracy of the relay protection besides the large amounts of faults to be collected and processed. The transmission line parameter (Line length $=29 \mathrm{~km}$, Line angle $=68^{\circ}$, line reactance $=0.3304 \Omega / \mathrm{km}$ ), Zero sequence compensation factor $\left(R_{E} / R_{L}=0.29, X_{E} / X_{L}=0.67\right)$, and fault resistance must also be taken into account. The zone settings of this transmission line are calculated by the central region load dispatch center in Vietnam ensuring that they are properly coordinated with the adjacent system and comply with the existing guidelines. The three zones of quadrilateral characteristic used to protect transmission line are explained in Table I [5]. We used the DIGSI operating software to enter configuration settings in the relay, it can automatically draw a relay operating characteristic graph as shown in Figure 3. The quadrilateral characteristic permits separate setting of the reactance $\mathrm{X}$ and the resistance $\mathrm{R}$. The resistance section $\mathrm{R}$ can be set separately for faults with and without earth involvement, therefore, this characteristic has an optimal performance in case of faults with fault resistance [6]. The effect of fault resistance on the reach of distance relays is better discussed with the simulation results.

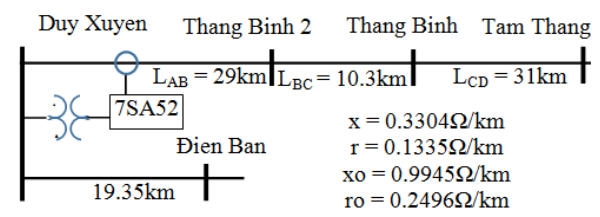

Fig. 2. The $110 \mathrm{kV}$ power system

TABLE I. PARAMETER SETTING ON SIEMENS 7SA522 ON A 110KV DUY XUYEN-THANG BINH OVERHEAD LINE

\begin{tabular}{|c|c|c|}
\hline \multirow{2}{*}{ Zone } & \multicolumn{2}{|r|}{ Relay Setting } \\
\hline & Setting & Value \\
\hline Zone 1 & $\begin{array}{l}\text { Covers } 85 \% \mathrm{AB} \text {, } \\
\text { forward direction } \\
(0.85 \mathrm{ZAB})\end{array}$ & $\begin{array}{c}\text { Operating Mode Z1: Forward } \\
\text { X(Z1), Rectance: } 8.14 \Omega \\
\mathrm{R}(\mathrm{Z} 1) \text {, Resistance for Ph-Ph faults: } 30 \Omega \\
\mathrm{RE}(\mathrm{Z} 1) \text {, Resistance for Ph-E faults: } 40 \Omega \\
\text { tZ1, Delay for fault: } 0 \mathrm{~s}\end{array}$ \\
\hline Zone 2 & $\begin{array}{c}\text { Covers } 100 \% \mathrm{AB}+ \\
60 \% \mathrm{BC}, \text { forward } \\
\text { direction }(\mathrm{ZAB}+ \\
0.6 \mathrm{ZBC})\end{array}$ & $\begin{array}{c}\text { Operating Mode Z2: Forward } \\
\text { X(Z2), Rectance: } 11.5 \Omega \\
\mathrm{R}(\mathrm{Z} 2) \text {, Resistance for Ph-Ph faults: } 35 \Omega \\
\mathrm{RE}(\mathrm{Z} 2) \text {, Resistance for Ph-E faults: } 50 \Omega \\
\text { tZ2, Delay for fault: } 0.3 \mathrm{~s} \\
\end{array}$ \\
\hline Zone 3 & $\begin{array}{c}\text { Covers } 100 \% \mathrm{AB}+ \\
100 \% \mathrm{BC}+60 \% \mathrm{CD}, \\
\text { forward direction } \\
(\mathrm{ZAB}+\mathrm{ZBC}+ \\
0.6 \mathrm{ZCD}) \\
\end{array}$ & $\begin{array}{c}\text { Operating Mode Z3: Forward } \\
\text { X(Z3), Rectance: } 19.53 \Omega \\
\mathrm{R}(\mathrm{Z} 3) \text {, Resistance for Ph-Ph faults: } 40 \Omega \\
\mathrm{RE}(\mathrm{Z} 3) \text {, Resistance for Ph-E faults: } 55 \Omega \\
\text { tZ3, Delay for fault: } 1.5 \mathrm{~s}\end{array}$ \\
\hline
\end{tabular}

\section{POWER SYSTEM UNDER STUDY}

We model the power system that is supplied from both ends as shown in Figure 4. It uses Simulink to evaluate the distance protection function. The overhead line is $89.65 \mathrm{~km}$ long, and the system nominal operating voltage is $110 \mathrm{kV}, 50 \mathrm{~Hz}$.

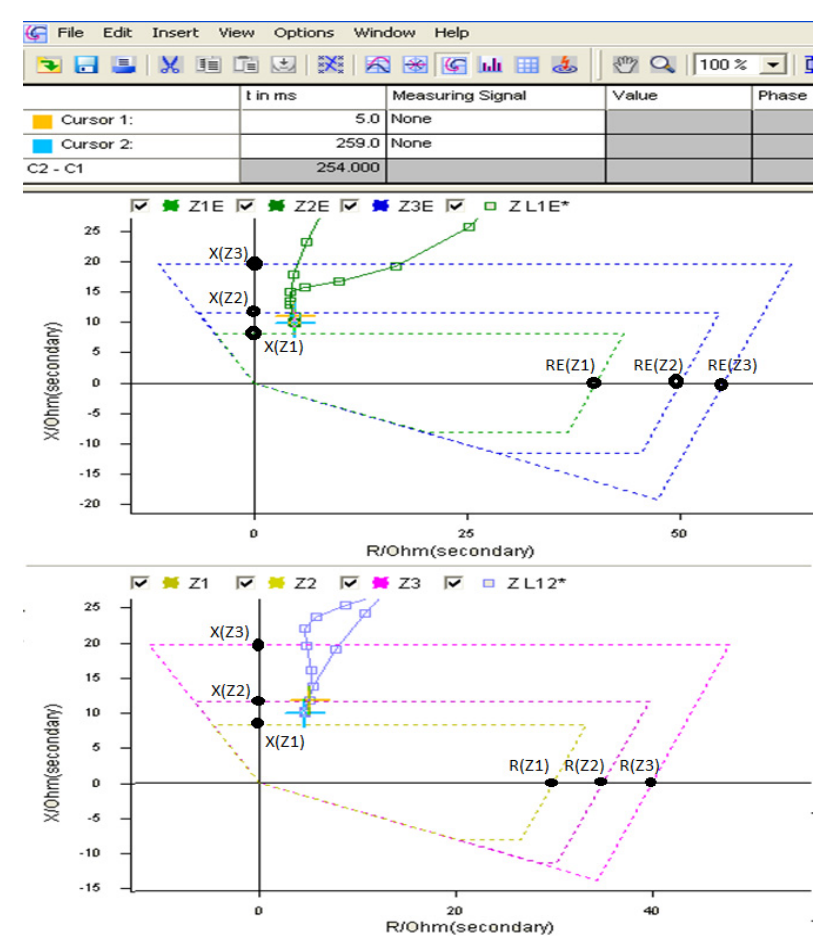

Fig. 3. Quadrilateral characteristic of Siemens 7 SA522 at the 171 overhead line of Duy Xuyen Substation

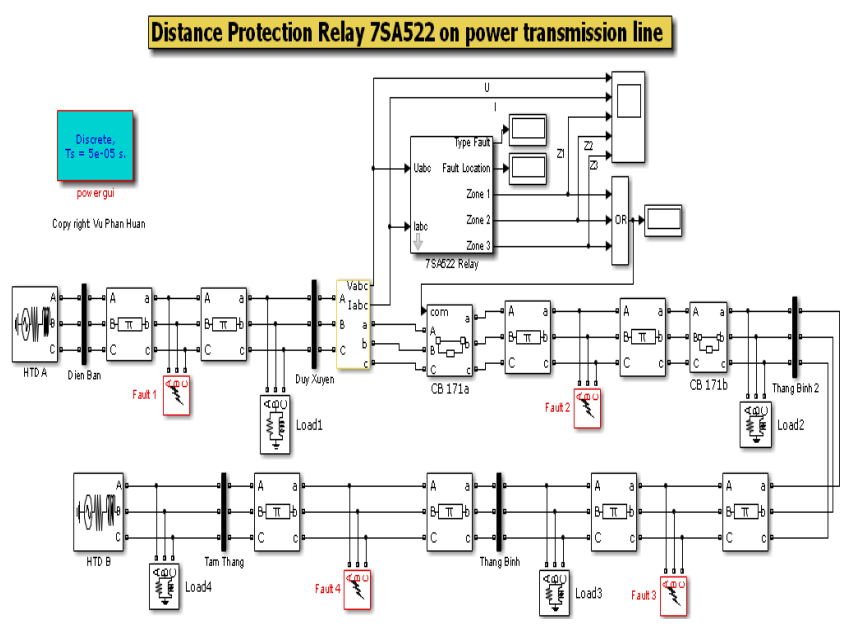

Fig. 4. Power system model

This model consists of:

1. The transmission line: three phase section line is used to represent the transmission line. Line sequence impedance is:

$\mathrm{R}_{\mathrm{L} 1}=0.1335 \Omega, \mathrm{R}_{\mathrm{L} 0}=0.2496 \Omega$.

$\mathrm{L}_{\mathrm{L} 1}=1.0517 \mathrm{mH}, \mathrm{L}_{\mathrm{L} 0}=3.1657 \mathrm{mH}$.

$\mathrm{C}_{\mathrm{L} 1}=0.038 \mu \mathrm{F}, \mathrm{C}_{\mathrm{L} 0}=0.038 \mu \mathrm{F}$. 
2. A load of $110 \mathrm{kV}, 35 \mathrm{MW}$, and $50 \mathrm{kVAR}$ is connected to the bus Duy Xuyen, Thang Binh, Thang Binh 2, Tam Thang.

3. Three phase fault block to deduce fault types and fault resistance varying from 1 to $40 \mathrm{ohms}$.

4. Three-phase measuring blocks to measure the three phase line, load current and voltage values.

5. The Scopes already support the display of five inputs (Voltages, Currents, Zones 1-3) of a simulated system, which allows a better signal comparison.

6. A Siemens 7SA522 relay is located at bus Duy Xuyen. It has been developed for fault detection, fault location, and distance protection which will be presented in section IV.

\section{DISTANCE PROTECTION RELAY SIEMENS 7SA522 MODEL}

The simulation model of the relay has been designed with four functional flow block diagrams (Figure 5) by using Matlab's Simulink library. Firstly, measurement block reads the values of voltage and current of each phase. Next, fault detection and classification are done by FD block and Fault Type block. Thirdly, impedance calculation block computes the value of $\mathrm{R}_{\mathrm{CAL}}$ and $\mathrm{X}_{\mathrm{CAL}}$. Afterwards, Trip_logic block checks operating logics. If all four conditions are satisfied then they issue a trip signal otherwise all steps are repeated from start to end. This helps us monitor and analyze data to avoid severe misunderstanding in assessing any use issues that arose during testing.

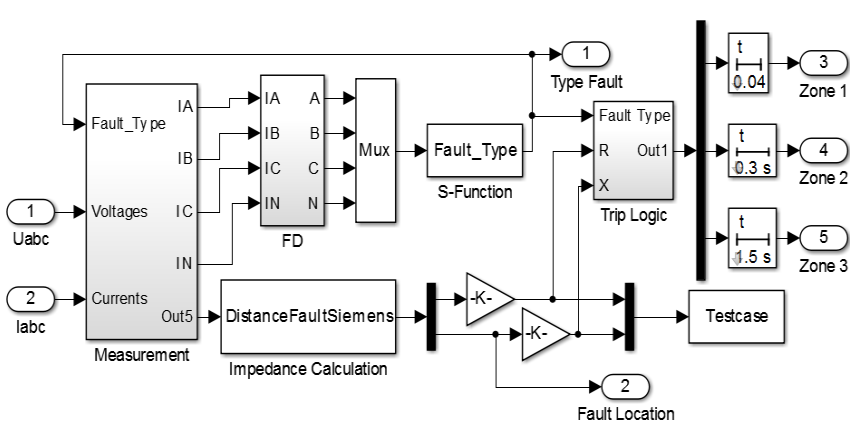

Fig. 5. Distance protection model

\section{A. Current and Voltage Measurement}

The measurement block receives two input signals corresponding to the three phase voltages and currents from $\mathrm{CT}, \mathrm{VT}$ and then it provides to the multiplexer to split the voltage and current signals into three single phase voltages and currents. After that, these quantities are passed through the Fourier transform block to avoid the higher order harmonics as shown in Figure 6.

\section{B. Fault Detection and Fault Classification}

According to the outputs of the measurement block $\left(\mathrm{I}_{\mathrm{A}}, \mathrm{I}_{\mathrm{B}}\right.$, $\mathrm{I}_{\mathrm{C}}$, and $\mathrm{I}_{\mathrm{N}}$ ), the fault detection in the transmission line is defined by the FD block. For earth current measurement, the fundamental component of the sum of the numerically filtered phase currents is supervised to detect if it exceeds the set value (parameter $3 \mathrm{I} 0>0.5 \mathrm{I}_{\mathrm{N}}$ ) then output " $\mathrm{N}$ " equals 1 . For phase current measurement, a fault occurrence is detected if $\mathrm{I}_{\mathrm{A}}, \mathrm{I}_{\mathrm{B}}$, or $\mathrm{I}_{\mathrm{C}}$ is greater than the threshold $1.3 \mathrm{I}_{\text {Norm }}$. Then output " $\mathrm{A}$ ", or " $\mathrm{B}$ ", or " $\mathrm{C}$ " is equal to 1 [7]. Based on the information above, fault type block performs fault classifying on the transmission line which can be summarized as in Table II.

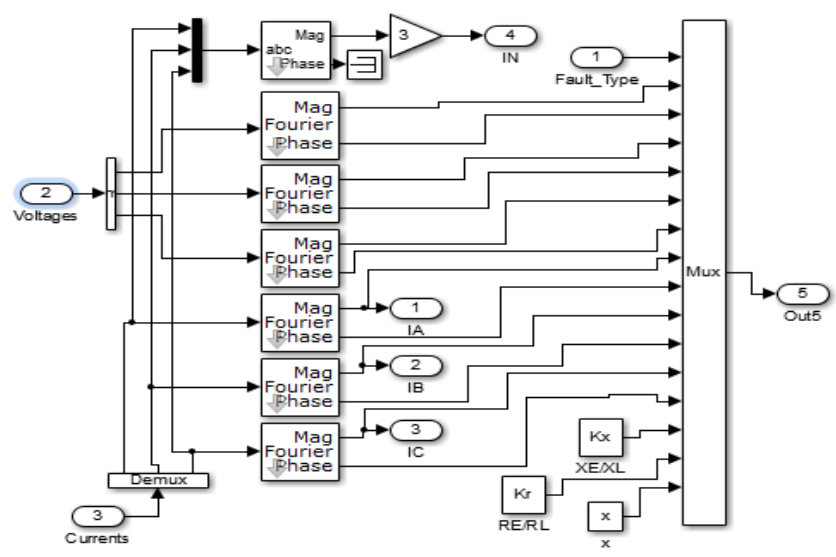

Fig. 6. Measurement block

TABLE II. FAULT TYPE CLASSIFICATION

\begin{tabular}{|c|c|c|c|c|c|}
\hline No & Type fault & A & B & C & N \\
\hline 1 & AG & 1 & 0 & 0 & 1 \\
\hline 2 & BG & 0 & 1 & 0 & 1 \\
\hline 3 & CG & 0 & 0 & 1 & 1 \\
\hline 4 & AB & 1 & 1 & 0 & 0 \\
\hline 5 & BC & 0 & 1 & 1 & 0 \\
\hline 6 & CA & 1 & 0 & 1 & 0 \\
\hline 7 & ABG & 1 & 1 & 0 & 1 \\
\hline 8 & BCG & 0 & 1 & 1 & 1 \\
\hline 9 & CAG & 1 & 0 & 1 & 1 \\
\hline 10 & ABC & 1 & 1 & 1 & \\
\hline
\end{tabular}

\section{Impedance Calculation}

To calculate the $\mathrm{R}_{\mathrm{CAL}}, \mathrm{X}_{\mathrm{CAL}}$ of relay protection, it uses one of the six loop measurements (AG, BG, CG, AB, BC, and CA) listed in Table III. The measured fault loop is necessary to know the fault type, local voltages and currents along with the zero sequence compensation factors. The following equations are employed to evaluate the measured values [7]. For the calculation of the phase-to-earth loop, for example during an AG short-circuit (Figure 7) it must be noted that the impedance of the earth return path does not correspond to the impedance of the phase. In the faulted loop the voltage $A G$, the phase current $\mathrm{I}_{\mathrm{A}}$ and the earth current $\mathrm{I}_{\mathrm{E}}$ are measured. The impedance to the fault location results from:

$$
R_{A}=\frac{U_{A}}{I_{A}} \frac{\cos \left(\varphi_{U}-\varphi_{A}\right)-\frac{I_{E}}{I_{A}} \frac{X_{E}}{X_{L}} \cos \left(\varphi_{U}-\varphi_{E}\right)}{1-\left(\frac{X_{E}}{X_{L}}+\frac{R_{E}}{R_{L}}\right) \frac{I_{E}}{I_{A}} \cos \left(\varphi_{E}-\varphi_{A}\right)+\frac{R_{E}}{R_{L}} \frac{X_{E}}{X_{L}}\left(\frac{I_{E}}{I_{A}}\right)^{2}}
$$




$$
X_{A}=\frac{U_{A}}{I_{A}} \frac{\sin \left(\varphi_{U}-\varphi_{A}\right)-\frac{I_{E}}{I_{A}} \frac{R_{E}}{R_{L}} \sin \left(\varphi_{U}-\varphi_{E}\right)}{1-\left(\frac{X_{E}}{X_{L}}+\frac{R_{E}}{R_{L}}\right) \frac{I_{E}}{I_{A}} \cos \left(\varphi_{E}-\varphi_{A}\right)+\frac{R_{E}}{R_{L}} \frac{X_{E}}{X_{L}}\left(\frac{I_{E}}{I_{A}}\right)^{2}}
$$

TABLE III. SHORT CIRCUIT TYPES AND FAULT LOOPS FOR THE DISTANCE MEASUREMENT

\begin{tabular}{|c|c|c|c|}
\hline No & Type fault & $\begin{array}{l}\text { Phases } \\
\text { involved }\end{array}$ & $\begin{array}{c}\text { Fault loop for distance } \\
\text { measurement }\end{array}$ \\
\hline \multirow{3}{*}{1} & \multirow{3}{*}{$\begin{array}{c}\text { Single phase to ground } \\
\text { fault }\end{array}$} & $\mathrm{AG}$ & $\mathrm{AG}$ \\
\hline & & BG & BG \\
\hline & & $\mathrm{CG}$ & $\mathrm{CG}$ \\
\hline \multirow{3}{*}{2} & \multirow{3}{*}{$\begin{array}{l}\text { Two phase short circuit } \\
\text { without ground }\end{array}$} & $\mathrm{AB}$ & $\mathrm{AB}$ \\
\hline & & $\mathrm{BC}$ & $\mathrm{BC}$ \\
\hline & & $\mathrm{CA}$ & $\mathrm{CA}$ \\
\hline \multirow{3}{*}{3} & \multirow{3}{*}{$\begin{array}{l}\text { Two phase short circuit } \\
\text { with ground }\end{array}$} & $\mathrm{ABG}$ & $\mathrm{AG}$, or $\mathrm{BG}$, or $\mathrm{AB}$ \\
\hline & & $\mathrm{BCG}$ & $\mathrm{BG}$, or $\mathrm{CG}$, or $\mathrm{BC}$ \\
\hline & & CAG & $\mathrm{AG}$, or $\mathrm{CG}$, or $\mathrm{CA}$ \\
\hline 4 & Three phase short circuit & $\mathrm{ABC}$ & $\mathrm{AB}$, or $\mathrm{BC}$, or $\mathrm{CA}$ \\
\hline
\end{tabular}

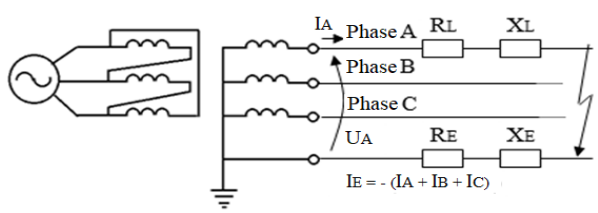

Fig. 7. Single-phase earth fault, fault loop

In (1) and (2), $U_{A}$ is the short-circuit voltage of phase $A, I_{A}$ is the short-circuit current of phase $A, I_{E}$ is the earth shortcircuit current, $\varphi_{\mathrm{U}}$ is phase angle of the short-circuit voltage, $\varphi_{\mathrm{A}}$ is phase angle of the phase short-circuit current, and $\varphi_{\mathrm{E}}$ is phase angle of the earth short-circuit current. To calculate the phaseto-phase loop for instance during a two-phase short circuit BC (Figure 8), the loop equation is:

$$
\begin{gathered}
R_{B C}=\frac{U_{B} I_{B} \cos \left(\varphi_{U_{B}}-\varphi_{I_{B}}\right)+U_{C} I_{C} \cos \left(\varphi_{U_{C}}-\varphi_{I_{C}}\right)}{I_{B}^{2}-2 I_{B} I_{C} \cos \left(\varphi_{I_{B}}-\varphi_{I_{C}}\right)+I_{C}^{2}}- \\
\frac{U_{B} I_{C} \cos \left(\varphi_{U_{B}}-\varphi_{I_{C}}\right)+U_{C} I_{B} \cos \left(\varphi_{U_{C}}-\varphi_{I_{B}}\right)}{I_{B}^{2}-2 I_{B} I_{C} \cos \left(\varphi_{I_{B}}-\varphi_{I_{C}}\right)+I_{C}^{2}} \\
X_{B C}=\frac{U_{B} I_{B} \sin \left(\varphi_{U_{B}}-\varphi_{I_{B}}\right)+U_{C} I_{C} \sin \left(\varphi_{U_{C}}-\varphi_{I_{C}}\right)}{I_{B}^{2}-2 I_{B} I_{C} \cos \left(\varphi_{I_{B}}-\varphi_{I_{C}}\right)+I_{C}^{2}}- \\
\frac{U_{B} I_{C} \sin \left(\varphi_{U_{B}}-\varphi_{I_{C}}\right)+U_{C} I_{B} \sin \left(\varphi_{U_{C}}-\varphi_{I_{B}}\right)}{I_{B}^{2}-2 I_{B} I_{C} \cos \left(\varphi_{I_{B}}-\varphi_{I_{C}}\right)+I_{C}^{2}} \\
\text { P }
\end{gathered}
$$

Fig. 8. Two-phase fault clear of earth, fault loop

In (3) and (4), $I_{B}$, and $I_{C}$ represents short circuit phase current of phase $B$, and $C$. $U_{B}$, and $U_{C}$ represents short circuit voltage of phase $\mathrm{B}$, and $\mathrm{C}$. $\varphi_{\mathrm{UB}}, \varphi_{\mathrm{UC}}$ are considered as phase angle of $\mathrm{U}_{\mathrm{B}}, \mathrm{U}_{\mathrm{C}}$. $\varphi_{\mathrm{IB}}, \varphi_{\mathrm{IC}}$ are considered as phase angle of $\mathrm{I}_{\mathrm{B}}, \mathrm{I}_{\mathrm{C}}$.

\section{Logic Decision}

As mentioned in the description of the calculation impedance, the calculated $\mathrm{R}_{\mathrm{CAL}}$ and $\mathrm{X}_{\mathrm{CAL}}$ coordinate values define a point on the complex impedance plane. The logic decision compares the point with the quadrilateral characteristics of the relay, shown in Figure 3. For example, the distance characteristic has been programmed as seen in Figure 9 [7]. The point $R_{3}$ and $X_{3}$ are the setting points for Zone 3 . The time settings $t_{\mathrm{z} 3}=1.5 \mathrm{~s}$. If a measured impedance point is inside the Zone 3, then the delay time can be started and when the impedance stays longer than $\mathrm{t}_{\mathrm{z} 3}$, the logic decision generates the true value of the related output binary signal. It means that relay will trip with Zone 3 if the following conditions are met:

- Condition 1:

$$
\left\{\begin{array}{l}
-\frac{R_{3}}{\operatorname{cotan} 22^{0}+\operatorname{cotan} 68^{0}}<X_{C A L}<X_{3} \\
R_{3}-\frac{R_{3}}{\left(\operatorname{cotan} 22^{0}+\operatorname{cotan} 68^{0}\right) \times \tan 68^{0}}<R_{C A L}<R_{3}+X_{3} \tan 68^{0} \\
R_{C A L}<R_{3}+X_{C A L} \tan 68^{0}
\end{array}\right.
$$

- Condition 2:

$$
\left\{\begin{array}{l}
-\frac{R_{3}}{\operatorname{cotan} 22^{0}+\operatorname{cotan} 68^{0}}<X_{C A L}<X_{3} \\
0<R_{C A L}<R_{3}-\frac{R_{3}}{\left(\operatorname{cotan} 22^{0}+\operatorname{cotan} 68^{\circ}\right) \times \tan 68^{0}} \\
R_{C A L}>X_{C A L} \tan 22^{0}
\end{array}\right.
$$

- Condition 3:

$$
\left\{\begin{array}{l}
0<X_{C A L}<X_{3} \\
-X_{C A L} \tan 30^{\circ}<R_{C A L}<0
\end{array}\right.
$$

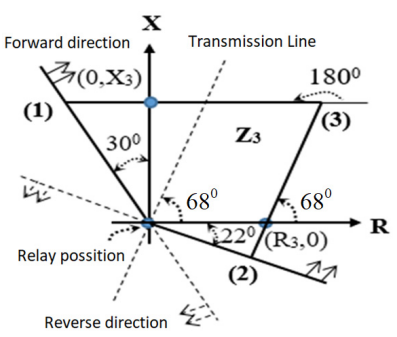

Fig. 9 . Zone 3 protection

\section{Simulation RESUltS}

After the building of the proposed model has been completed, it is ready to analyze the secure operation of the quadrilateral characteristics of the three protection zones applied with variation in fault parameters like fault types, fault location from $-5 \mathrm{~km}$ to $50 \mathrm{~km}$, fault resistance from $1 \Omega$ to 40 $\Omega$. During a fault, the current in the faulted phases increases. The voltage in the faulted phases decreases beginning at $0.3 \mathrm{~s}$. 
Distance protection zone outputs such as Z1, Z2, Z3, operate when the corresponding pre-set times are reached. After $10 \mathrm{~ms}$ the line is tripped and the voltage begins to recover. In case of an AG fault with $R_{F}=30 \Omega$ is created on the line Duy XuyenThang Binh at a distance of $35 \mathrm{~km}$ from Duy Xuyen bus (forward direction). The distance represents $120.7 \%$ of the line length. Figure 10 shows the current and voltage waveform and a trip signal of protection zones before, during and after a fault. The fault occurs at $0.3 \mathrm{~s}$, the current of phase $\mathrm{A}$ is increased and voltage of phase $\mathrm{A}$ is decreased. As a result, impedance trajectory seen by the relay entered into the characteristic second zone. Fault location displays $28.38 \mathrm{~km}$. Relay takes $0.31 \mathrm{~s}$ to send trip signal $\mathrm{Z} 2$ to the circuit breaker.

Figure 11 shows the operation of relay in zone 1 with the presence of $A B$ fault at distance $15 \mathrm{~km}$ with $\mathrm{R}_{\mathrm{F}}=10 \Omega$. The distance represents $51.7 \%$ of the line length. According to the change in voltage and current waveforms during the fault, the impedance trajectory moves quickly into Zone 1, fault location displays $14.29 \mathrm{~km}$ which results in a tripping at $0.322 \mathrm{~s}$. In Figure 12, the result is shown where BCG fault is applied on the transmission line at distance $45 \mathrm{~km}$ with $\mathrm{R}_{\mathrm{F}}=40 \Omega$. According to the change in voltage and current waveforms during the fault, the apparent impedance seen at relay point is reduced but the trip signals are deactivated due to the movement of impedance trajectory out of Zone 3 area. Fault location displays $37.65 \mathrm{~km}$. As shown in Figure 13, at $0.3 \mathrm{~s}$ an $\mathrm{ABC}$ fault occurs on the transmission line at $50 \mathrm{~km}, \mathrm{R}_{\mathrm{F}}=1 \Omega$, and the fault duration is $1.5 \mathrm{~s}$. According to the change in voltage and current waveforms during fault, relay impedance trajectory into Zone 3, fault location displays $49.47 \mathrm{~km}$, thus trip signal $\mathrm{Z} 3$ is activated at $1.81 \mathrm{~s}$. Some of the results for various fault cases $(\mathrm{AG}, \mathrm{BC}, \mathrm{ABG}$, and $\mathrm{ABC})$ are given in Table IV.

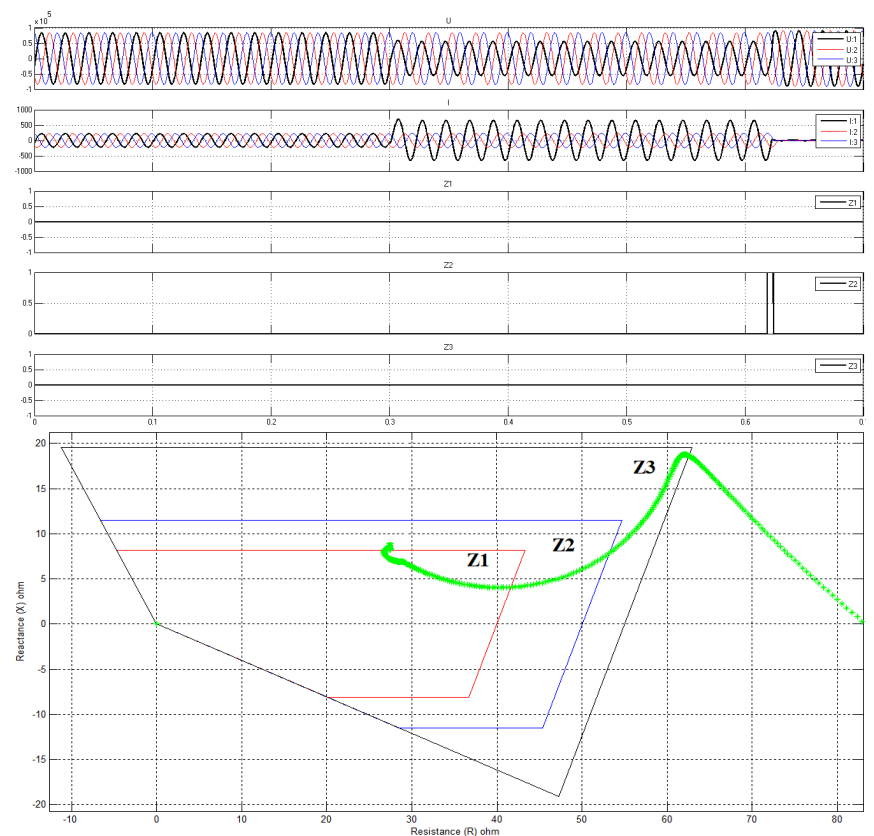

Fig. 10. Voltage, current waves, trip sinals and impedance trajectory for faults at $A G$ fault with $R_{F}=30 \Omega$ at $35 \mathrm{~km}$ from relay point

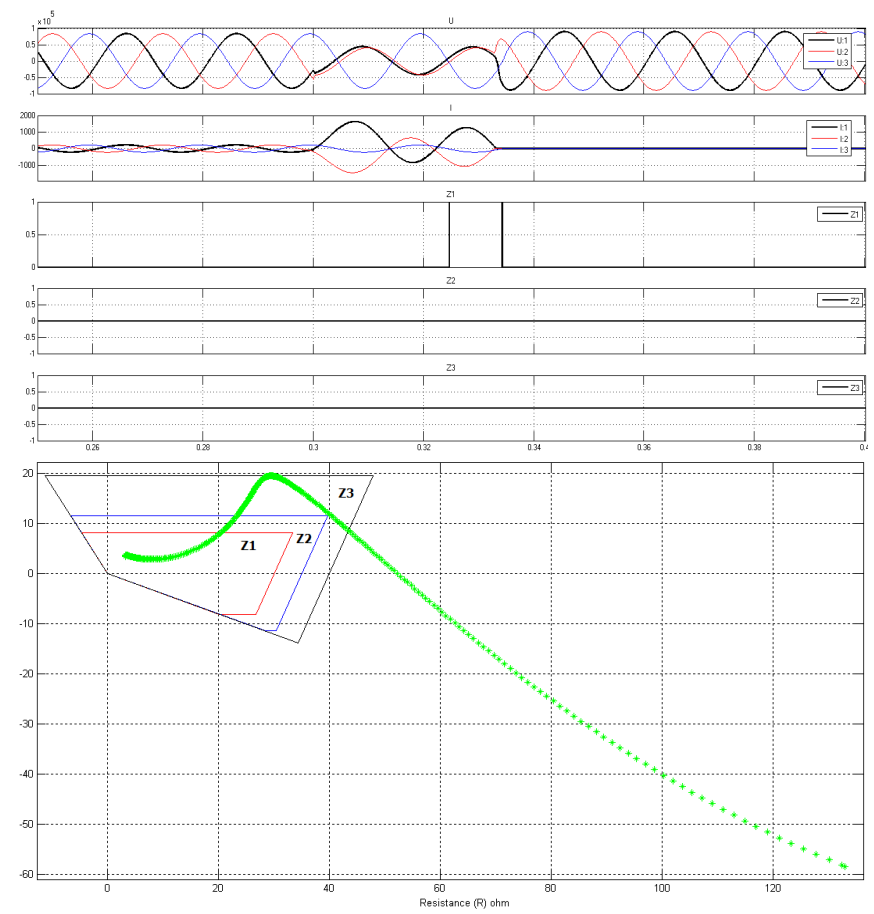

Fig. 11. Voltage, current waves, trip sinals and and impedance trajectory for $\mathrm{AB}$ fault with $\mathrm{R}_{\mathrm{F}}=10 \Omega$ at $15 \mathrm{~km}$ from relay point

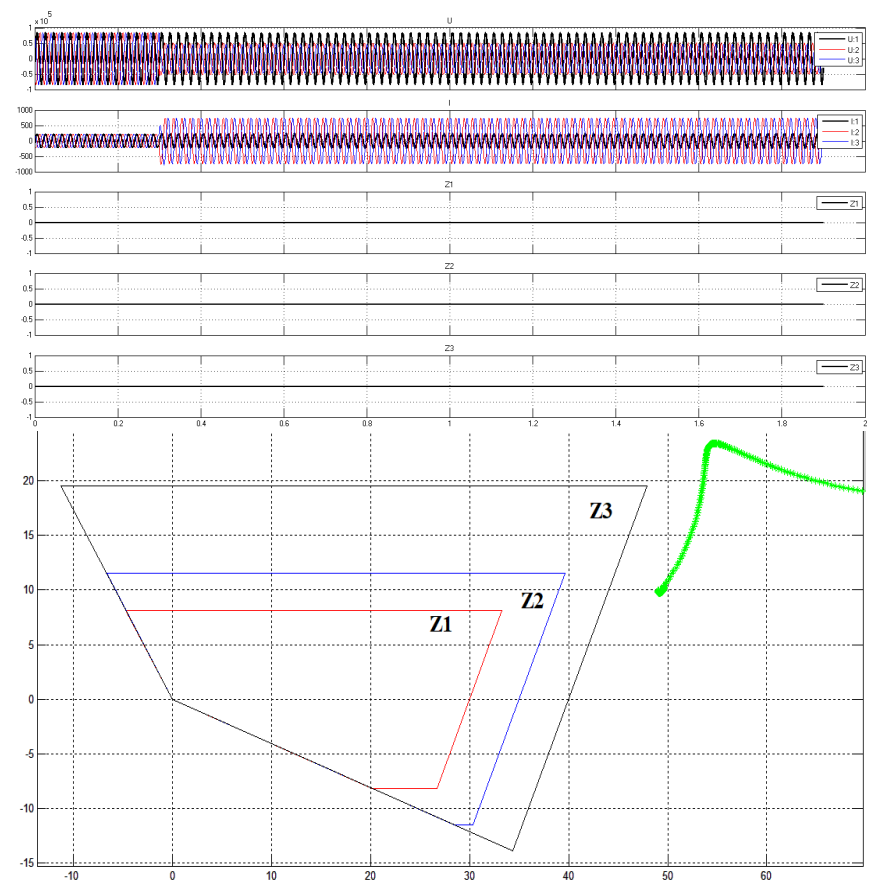

Fig. 12. Voltage, current waves, trip sinals and impedance trajectory for faults at BCG fault with $\mathrm{R}_{\mathrm{F}}=40 \Omega$ at $45 \mathrm{~km}$ from relay point.

The power system is supplied from both ends, its setting for Zone 1 is 85 percent of line length or $24.65 \mathrm{~km}$. Similarly, Zone 2 is $35.18 \mathrm{~km}$, and Zone 3 is $57.9 \mathrm{~km}$. In the tests, the fault resistance influence on the measured distance to fault location, the highest fault resistance that allowed for reliable distance protection relay is $20 \Omega$. In the case of the high 
resistance fault, this value changes from 20 to $25 \Omega$, the final point of fault impedance locus falls under Zone 1 characteristic or under-reaching tendency. If it is higher than $40 \Omega$, fault impedance locus out of zone protection with corresponding error increases.

TABLE IV. TEST RESULTS

\begin{tabular}{|c|c|c|c|c|}
\hline Phase & $\begin{array}{c}\text { Actual fault } \\
\text { location (km) }\end{array}$ & $\begin{array}{c}\text { Fault } \\
\text { resistance }(\Omega)\end{array}$ & $\begin{array}{l}\text { Measured fault } \\
\text { location (km) }\end{array}$ & $\begin{array}{c}\text { Zone } \\
\text { trip }\end{array}$ \\
\hline \multirow{11}{*}{ AG } & -5 & 10 & -12.2 & 1 \\
\hline & 5 & 1 & 4.718 & $\mathrm{Z1}$ \\
\hline & 10 & 5 & 9.244 & $\mathrm{Z1}$ \\
\hline & 15 & 10 & 13.7 & $\mathrm{Z1}$ \\
\hline & 20 & 15 & 18.21 & $\mathrm{Z1}$ \\
\hline & 25 & 20 & 22.78 & $\mathrm{Z1}$ \\
\hline & 30 & 25 & 24.75 & $\mathrm{Z1}$ \\
\hline & 35 & 30 & 31.42 & $\mathrm{Z} 2$ \\
\hline & 40 & 35 & 35.25 & $\mathrm{Z} 2$ \\
\hline & 45 & 40 & 38.35 & 1 \\
\hline & 50 & 1 & 49.67 & $\mathrm{Z3}$ \\
\hline \multirow{11}{*}{$\mathrm{AB}$} & -5 & 10 & -9.475 & 1 \\
\hline & 5 & 1 & 4.923 & $\mathrm{Z1}$ \\
\hline & 10 & 5 & 9.633 & $\mathrm{Z1}$ \\
\hline & 15 & 10 & 14.29 & $\mathrm{Z1}$ \\
\hline & 20 & 15 & 18.96 & $\mathrm{Z1}$ \\
\hline & 25 & 20 & 23.63 & $\mathrm{Z1}$ \\
\hline & 30 & 25 & 28.15 & $\mathrm{Z1}$ \\
\hline & 35 & 30 & 31.92 & $\mathrm{Z} 2$ \\
\hline & 40 & 35 & 35.31 & $\mathrm{Z} 2$ \\
\hline & 45 & 40 & 37.65 & 1 \\
\hline & 50 & 1 & 49.47 & $\mathrm{Z3}$ \\
\hline \multirow{11}{*}{$\mathrm{BCG}$} & -5 & 10 & -9.455 & 1 \\
\hline & 5 & 1 & 4.919 & $\mathrm{Z1}$ \\
\hline & 10 & 5 & 9.919 & $\mathrm{Z1}$ \\
\hline & 15 & 10 & 14.92 & $\mathrm{Z1}$ \\
\hline & 20 & 15 & 19.93 & $\mathrm{Z1}$ \\
\hline & 25 & 20 & 23.62 & $\mathrm{Z1}$ \\
\hline & 30 & 25 & 28.14 & $\mathrm{Z1}$ \\
\hline & 35 & 30 & 31.91 & $\mathrm{Z2}$ \\
\hline & 40 & 35 & 35.31 & $\mathrm{Z} 2$ \\
\hline & 45 & 40 & 37.65 & 1 \\
\hline & 50 & 1 & 49.47 & $\mathrm{Z3}$ \\
\hline \multirow{11}{*}{$\mathrm{ABC}$} & -5 & 10 & -9.48 & 1 \\
\hline & 5 & 1 & 4.919 & $\mathrm{Zl}$ \\
\hline & 10 & 5 & 9.633 & $\mathrm{Zl}$ \\
\hline & 15 & 10 & 14.29 & $\mathrm{Zl}$ \\
\hline & 20 & 15 & 18.95 & $\mathrm{Z1}$ \\
\hline & 25 & 20 & 23.62 & $\mathrm{Z1}$ \\
\hline & 30 & 25 & 28.15 & $\mathrm{Z1}$ \\
\hline & 35 & 30 & 31.92 & $\mathrm{Z2}$ \\
\hline & 40 & 35 & 35.31 & $\mathrm{Z2}$ \\
\hline & 45 & 40 & 37.65 & 1 \\
\hline & 50 & 1 & 49.47 & $\mathrm{Z3}$ \\
\hline
\end{tabular}

\section{CONCLUSIONS}

In this study, the distance protection function with three forward zones has been implemented in a Siemens 7SA522 distance protection relay on the $110 \mathrm{kV}$ Duy Xuyen-Thang Binh transmission line that was simulated easily and reliably in Matlab Simulink. The proposed model allows us to include the detailed analysis of the impedance $\left(\mathrm{R}_{\mathrm{CAL}}, \mathrm{X}_{\mathrm{CAL}}\right)$ measured by the distance relay on one single end, fault detection, fault classification, and tripping protection zones for fault, considering fault location, fault type existing on the transmission line, and fault resistance. According to the obtained results, it has been shown that the accuracy of the relay depends on a fault resistance value. The high fault resistance causes the distance relay to over-reach or underreach. Therefore, a correctly set distance protection relay can correctly compute the fault location, mitigate the problem of mal-operation, thus ensuring effective and reliable protection to the transmission line.

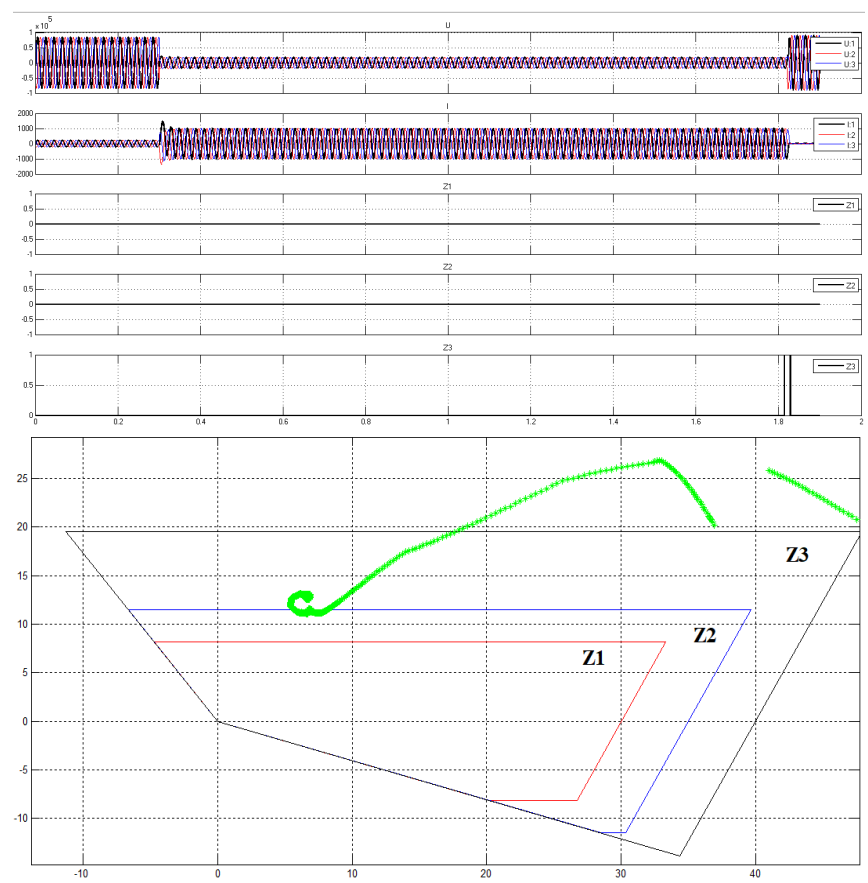

Fig. 13. Voltage, current waves, trip sinals and impedance trajectory for faults at $\mathrm{ABC}$ fault with $\mathrm{RF}=1 \Omega$ at $50 \mathrm{~km}$ from relay point

\section{ACKNOWLEDGMENT}

Authors would like to thank the "Electrical Testing Company Limited, Viet Nam" for allowing the use of the project of relay protection used in this study.

\section{REFERENCES}

[1] O. Muhayimana, Distance Protection for Parallel and Double-Circuit HV Lines, MSc Thesis, Brno University Of Technology, 2016

[2] V. H. Makwana, B. R. Bhalja, Transmission Line Protection using digital technology, Springer, 2016

[3] T. Saengsuwan, "Modelling of distance relays in EMTP", IPST'99 International Conference on Power Systems Transients, Budapest Hungary, pp. 213-217, June 20-24, 1999

[4] L. K. Hung, N. H. Viet, V. P. Huan, "The effect of fault resistance on the performance of distance relay protection", The 2011 International Symposium on Electrical-Electronics Engineering, Ho Chi Minh City, Vietnam, pp. 238-244, November 8-9, 2011

[5] Central Region Load Dispatch Center, Setting calculation of distance protection relay Siemens 7SA522 at 171 overhead line of Duy Xuyen Substation, Decision No A3-03-2015/DUX110, Siemens, 2015

[6] G. Ziegler, Numerical Distance Protection: Principles and Applications, John Wiley \& Sons, 2011 